\title{
On the Strengthening Mechanism by Warm Working*
}

\author{
By Isao Gokyu** and Kenji Hashimoto***
}

\begin{abstract}
The yield point and the tensile strength of steels worked at elevated temperatures (about $300^{\circ} \mathrm{C}$ ) are higher than those of steels worked at room temperature or of steels annealed at various temperatures after cold working. It can be considered that strengthening of steel by warm working is attributed to the strengthening of $\alpha$-iron in steel; the dislocation density of $\alpha$-iron worked at elevated temperatures is higher than that of $\alpha$-iron cold worked or annealed after cold working because of the multiplication of dislocations due to dynamic strain aging in warm working. $0.02 \% \mathrm{C} \alpha$-iron warm worked, cold worked and annealed after cold working is studied, respectively, by means of transmission microscopy and the hardness test.

The results obtained are as follows :

(1) Both the low temperature annealing effect after cold working and the warm working contribute mostly to the strengthening of $0.02 \% \mathrm{C} \alpha$-iron in the same way as for other steels, so that the strengthening mechanism of $0.02 \% \mathrm{C} \alpha$-iron is considered to be the same as that of other steels.

(2) The strength of the warm-worked steel is higher than that of the steel annealed at various temperatures for various times after cold working.

(3) The dislocation density of $\alpha$-iron worked at $300^{\circ} \mathrm{C}$ is higher than that of $\alpha$-iron worked at other temperatures and annealed after cold working. The dislocation density of $\alpha$-iron corresponds to the hardness of $\alpha$-iron.

(4) The mechanism of strengthening $\alpha$-iron by warm working is based on the increase of the dislocation density by multiplication of dislocations due to dynamic strain aging.

(Received March 7, 1969)
\end{abstract}

\section{Introduction}

The yield point and the tensile strength of plain carbon steels $(0.06 \sim 0.85 \% \mathrm{C})$ and low alloying steels worked at elevated temperatures (about $300^{\circ} \mathrm{C}$ ) are higher than those of steels worked at room temperature or of steels annealed at various temperatures after cold working $^{(1)}$. Generally, the stregth of the alloy consisting of many phases is approximated by the product of the strength of each phase and the volume percentage of the phase ${ }^{(2)}$. $\alpha$-iron and carbide constitute plain carbon steel and low alloying steel. The strength of carbide being very large (700 800 in Vickers hardness), it can be considered that the strengthening of steel by warm working is attributed to the strengthening of $\alpha$ iron by warm working, whereas the strengthening of $\alpha$-iron is attributed to the higher dislocation density of $\alpha$-iron because of the multiplication of dislocations due to dynamic strain aging in warm working. In this study, $0.02 \%$ C $\alpha$-iron warm worked, cold worked and annealed after cold working is studied, respectively, by means of transmission microscopy and the hardness test to make clear this strengthening mechanism by warm working.

* This paper was originally published in Japanese in J. Japan Inst. Metals, 31 (1967), 352.

** Department of Metallurgy, Faculty of Engineering, University of Tokyo, Tokyo, Japan.

*** Department of Metallurgy, Faculty of Engineering, University of Tokyo, Tokyo. Present address : Furukawa Electric Company, Nikko Works, Nikko, Japan.

(1) I. Gokyu and K. Hashimoto : J. of Japan Society for Technology of Plasticity, 5(1964), 643.

(2) J.E. Dorn: Relation of Properties to Microstructure, (1954), ASM, p. 77.

\section{Experimental Materials and Procedure}

$\alpha$-iron $(0.02 \% \mathrm{C})$ melted in the HF furnace under a vacuum of $5 \times 10^{-4} \mathrm{mmHg}$ was supplied as a $600 \mathrm{~mm}$ dia. $\times 100 \mathrm{~mm}$ long ingot. These had been hot rolled to $6 \mathrm{~mm}$ thick, followed by machining to $3 \mathrm{~mm}$ thick, and then cold rolled to $1 \mathrm{~mm}$ thick and annealed at $750^{\circ} \mathrm{C}$ for $24 \mathrm{hr}$ in vacuum. These specimens was rolled to $0.96,0.87,0.80 \mathrm{~mm}$ in thickness at various temperatures between room temperature and $400^{\circ} \mathrm{C}$. Then, the specimen rolled at room temperature and $300^{\circ} \mathrm{C}$ were annealed at various temperatures between $100^{\circ}$ and $450^{\circ} \mathrm{C}$ for $10 \sim 10000 \mathrm{~min}$.

The hardness test was carried out on both the rolled and annealed specimens to obtain aging curves. The specimens rolled to $0.96 \mathrm{~mm}$ in thickness were further tested under a transmission microscope.

\section{Experimental Results and Discussion}

Fig. 1 shows the effect of rolling temperature on the hardness of $\alpha$-iron. The hardness increases with the rise of the rolling temperature up to $300^{\circ} \mathrm{C}$ but decreases at $400^{\circ} \mathrm{C}$. This is the same as the results for the plain carbon steels and low alloying steels. This means that the strengthening of the warm worked steel is due to the strengthening of the $\alpha$-iron worked at $300^{\circ} \mathrm{C}$.

The influence of annealing at various temperatures between $100^{\circ}$ and $450^{\circ} \mathrm{C}$ for various times on the hardness of cold worked $\alpha$-iron and warm worked $\alpha$-iron are shown in Figs. 2 9. From these curves, it is shown 


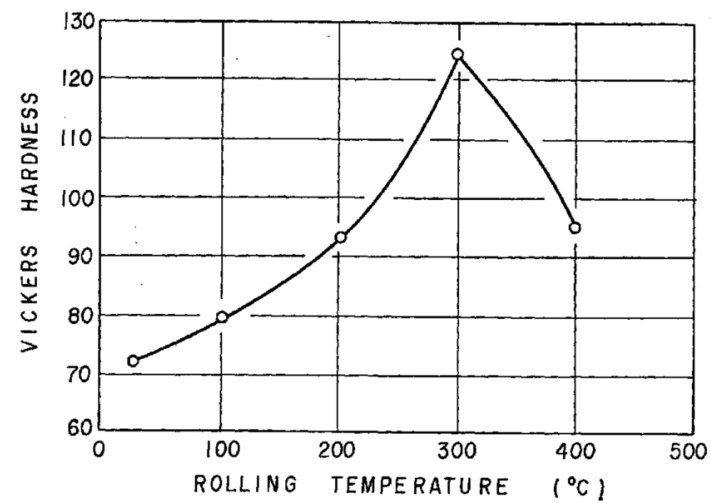

Fig.1 Effect of rolling temperature on hardness of $\alpha$-iron

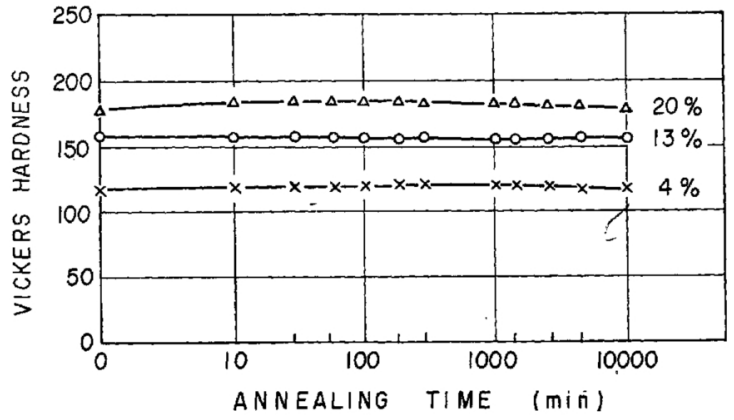

Fig.2 Relation between annealing time and hardness of cold worked $\alpha$-iron. Annealed at $100^{\circ} \mathrm{C}$

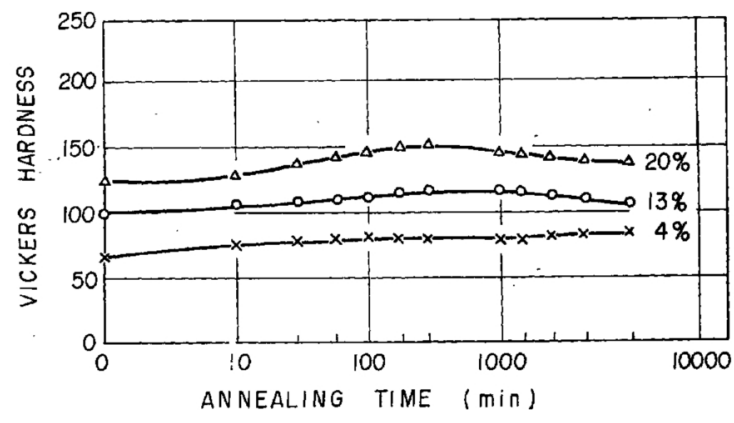

Fig.3 Relation between annealing time and hardness of cold worked $\alpha$-iron. Annealed at $200^{\circ} \mathrm{C}$

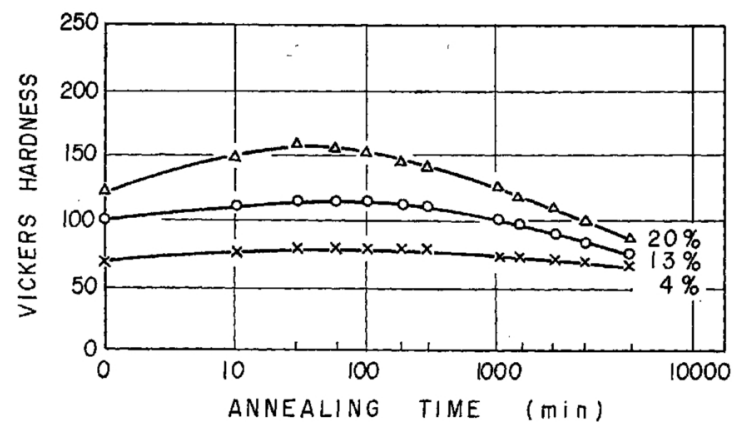

Fig.4 Relation between annealing time and hardness of cold worked $\alpha$-iron. Annealed at $300^{\circ} \mathrm{C}$

that the hardness of $\alpha$-iron worked at room temperature decreases after increasing, but that of $\alpha$-iron worked at $300^{\circ} \mathrm{C}$ decreases monotonously with the aging time. Comparing the hardness of $\alpha$-iron annealed after cold working with that of $\alpha$-iron worked at $300^{\circ} \mathrm{C}$, it is seen that the strength of the warm-worked steel is higher than that of the steel annealed at various temperatures for various times after cold working.

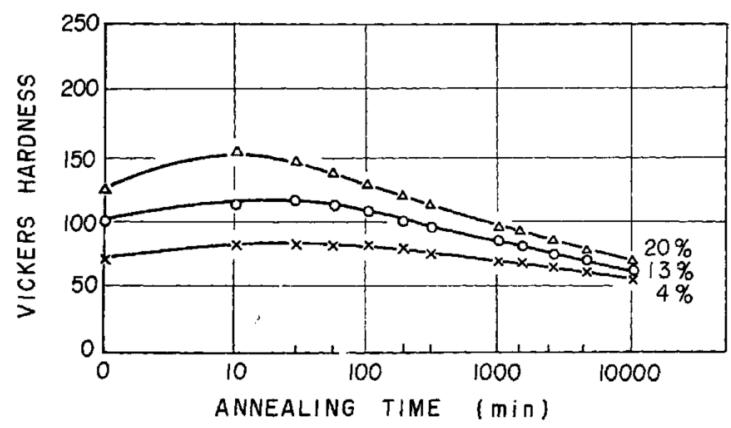

Fig.5 Relation between annealing time and hardness of cold worked $\alpha$-iron. Annealed at $450^{\circ} \mathrm{C}$

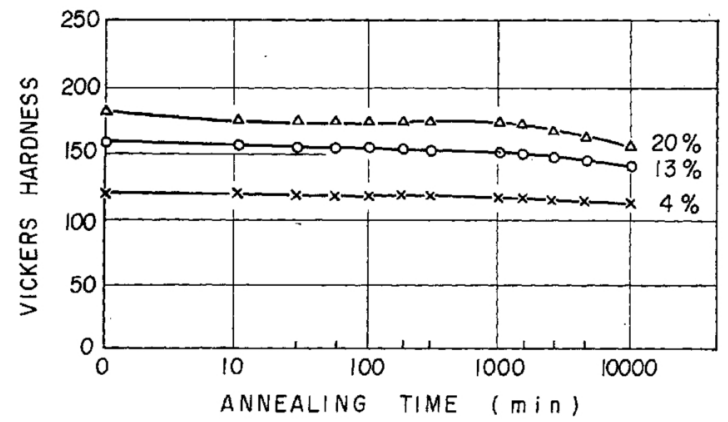

Fig.6 Relation between annealing time and hardness of warm worked $\alpha$-iron. Annealed at $100^{\circ} \mathrm{C}$

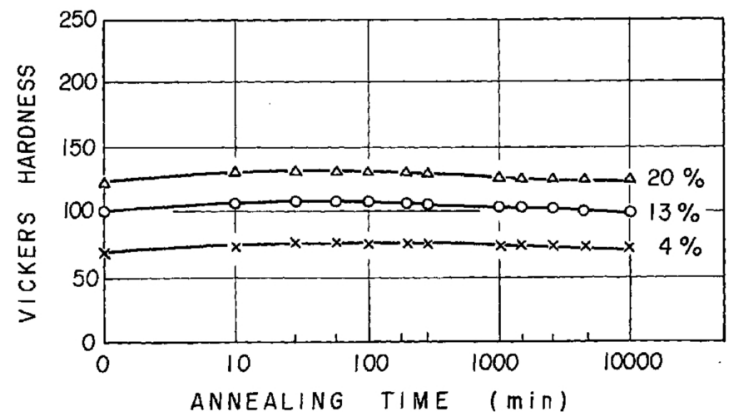

Fig.7 Relation between annealing time and hardness of warm worked $\alpha$-iron. Annealed at $200^{\circ} \mathrm{C}$

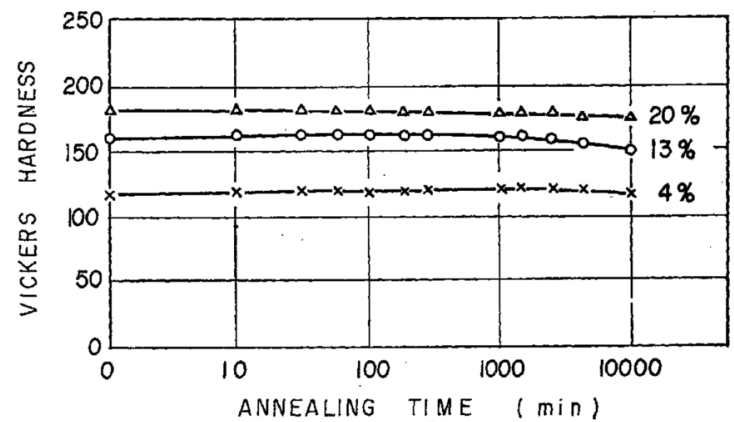

Fig.8 Relation between annealing time and hardness of warm worked $\alpha$-iron. Annealed at $300^{\circ} \mathrm{C}$

Photos. 1 6 show the typical transmission electron micrographs of $\alpha$-iron annealed at $700^{\circ} \mathrm{C}$ for $24 \mathrm{hr}$ (Photo. 1), rolled at room temperature to a thickness of $0.96 \mathrm{~mm}$ (Photo. 2), annealed at $300^{\circ} \mathrm{C}$ for $30 \mathrm{~min}$ after cold rolling (Photo. 3), and rolled at $200^{\circ} \mathrm{C}$ (Photo. 4), at $300^{\circ} \mathrm{C}$ (Photo. 5) and at $400^{\circ} \mathrm{C}$ (Photo. 6). As shown in these photographs, the number of dislocations in $\alpha$ iron annealed is small, but that in the rolled one in- 


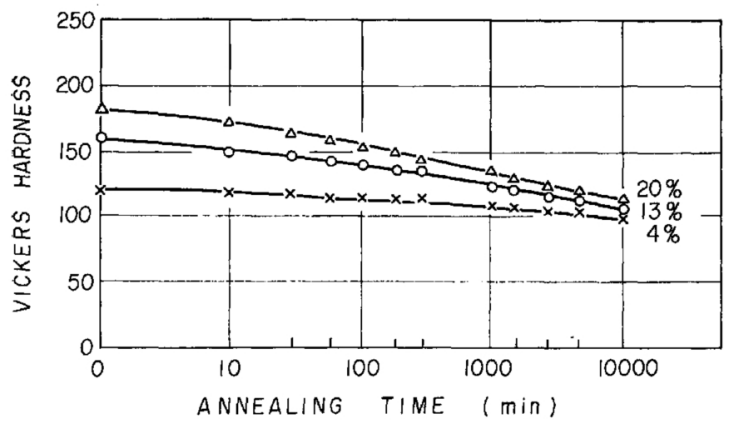

Fig.9 Relation between annealing time and hardness of warm worked $\alpha$-iron. Annealed at $450^{\circ} \mathrm{C}$

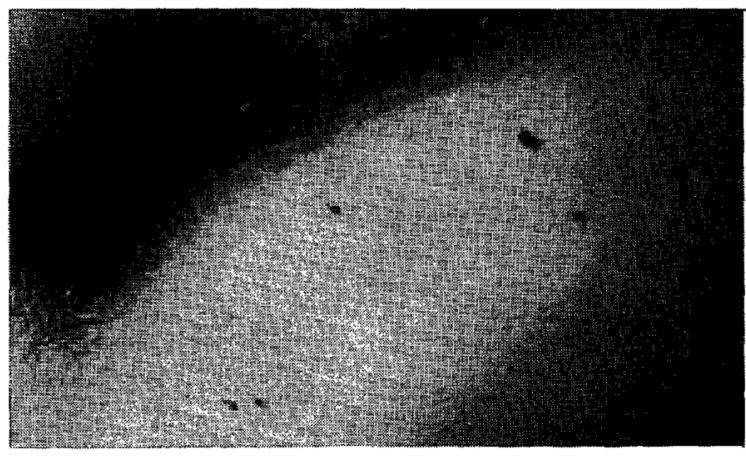

Photo.1 Transmission electron micrograph of $\alpha$-iron annealed at $700^{\circ} \mathrm{C}$ for $24 \mathrm{hr}(\times 12000 \times 2 \times 2 / 3)$

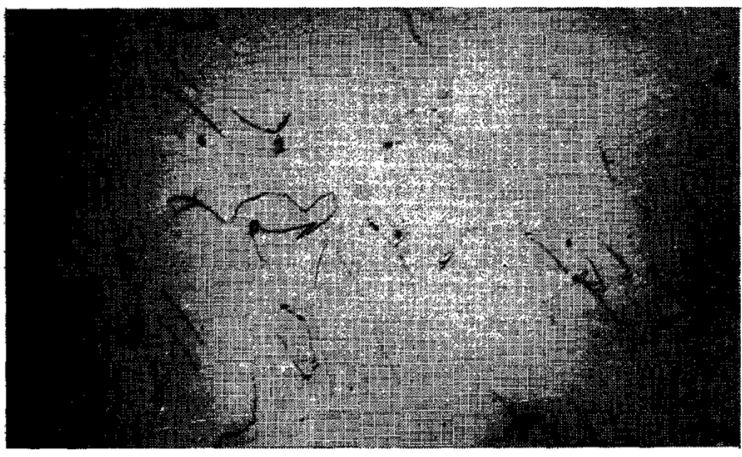

Photo.2 Transmission electron micrograph of $\alpha$-iron rolled at röjm temperature $(\times 12000 \times 2 \times 2 / 3)$

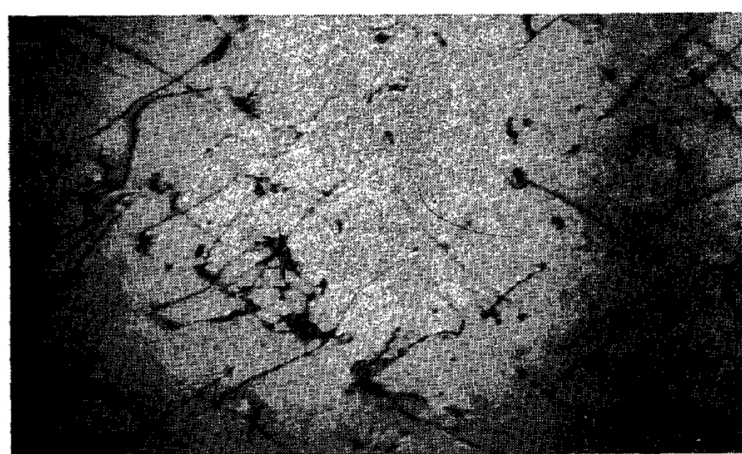

Photo.3 Transmission electron micrograph of $\alpha$-iron annealed at $300^{\circ} \mathrm{C}$ for 30 min after cold rolling $(\times 12000 \times 2 \times 2 / 3)$

creases with rising rolling temperature up to $300^{\circ} \mathrm{C}$ but decreases at $400^{\circ} \mathrm{C}$. Moreover, the number of dislocations in $\alpha$-iron annealed at $300^{\circ} \mathrm{C}$ after cold rolling is smaller than that of the warm rolled $\alpha$-iron. This coresponds to the behavior of the hardness change of the $\alpha$-iron annealed after cold rolling and rolled at

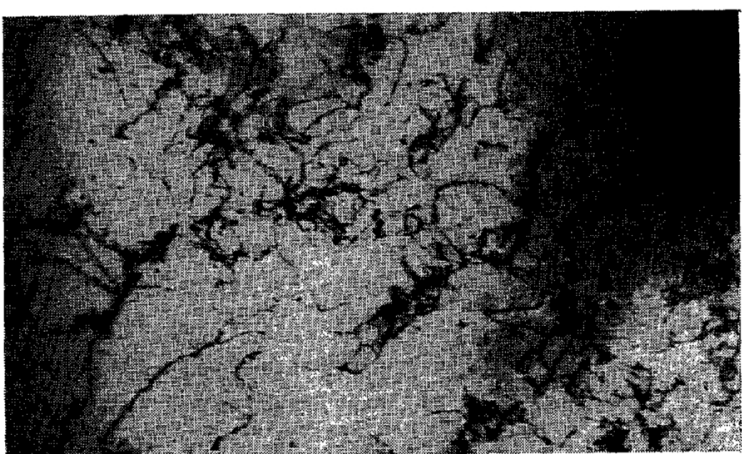

Photo.4 Transmission electron micrograph of $\alpha$-iron rolled at $200^{\circ} \mathrm{C}(\times 12000 \times 2 \times 2 / 3)$

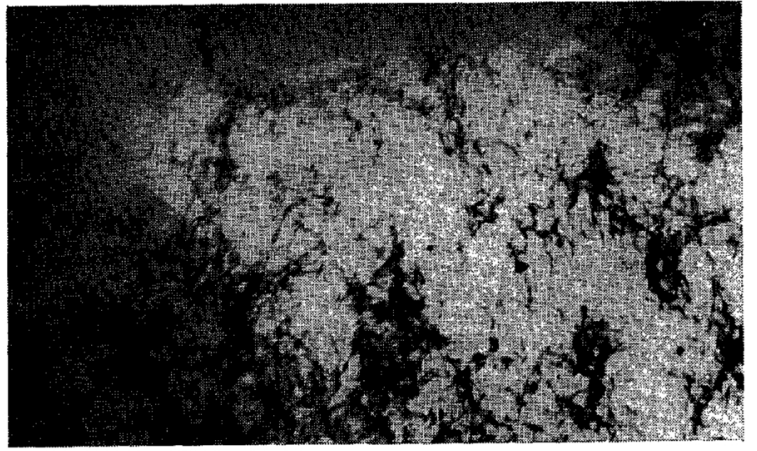

Photo.5 Transmission electron micrograph of $\alpha$-iron rolled at $300^{\circ} \mathrm{C}(\times 12000 \times 2 \times 2 / 3)$

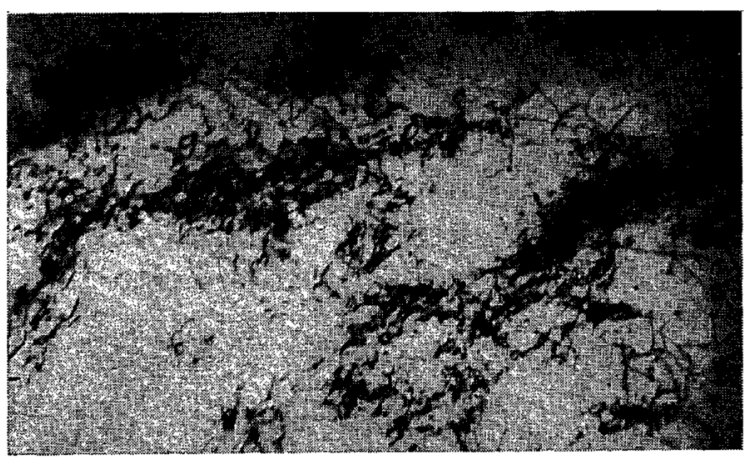

Photo. 6 Transmission electron micrograph of $\alpha$-iron rolled at $400^{\circ} \mathrm{C}(\times 12000 \times 2 \times 2 / 3)$

various temperatures.

Here we will discuss that the strength and the dislocation density of the warm worked steel is higher than that of the steel annealed after cold working.

It is known as "static strain aging" that the yield point of $\alpha$-iron increases when annealed at a suitable temperature and for an appropriate time after cold working. This is due to the reaction between the interstitial atom $\mathrm{C}$ in $\alpha$-iron and a dislocation produced by working(3). On the other hand, this strain aging can occur during working when the working temperature is elevated, and this is known as "dynamic strain aging". This dynamic strain aging differs from the static strain aging in the strengthening of $\alpha$-iron. During working at elevated temperatures, the moving dislocation produced by working reacts with the atom $\mathrm{C}$ and makes the Cottrell atmosphere. The yielding of $\alpha$-iron which has the atmosphere does not occur due to

(3) C. A. Edwards : The Struclure and Properties of Mild Steel, (1952), p. 79. 
the breakdown of the atmosphere but to the multiplication of the dislocations newly produced by working(4). On working at elevated temperatures, therefore, the repetition of dynamic strain aging and multiplication occur. This brings about the increase in dislocation density, that is, the strengthening of $\alpha$-iron.

The increase of dislocations depends upon the working temperature and the strain rate because the Cottrell atmosphere does not occur when dislocations move faster than the diffusion velocity of the interstitial atom $\mathrm{C}$ and dislocations drag the atom $\mathrm{C}$ when the working temperature is too high $^{(5)}$.

The relation among strain rate $(\dot{\varepsilon})$, the diffusion velocity of the interstitial atom $\mathrm{C}(D)$, and the dislocation density $(\rho)$ is as follows ${ }^{(5)}$ :

$$
\dot{\varepsilon} \simeq D \rho \text {. }
$$

The mean strain rate in the case of this study can be calculated from the following equation ${ }^{(6)}$ :

$$
W_{m}=V \ln h_{i} / h_{0} / \sqrt{R \Delta h}
$$

where $\mathrm{R}=$ radius of rolls $=160 \mathrm{~mm}$

$V=$ angular velosity of rolls $=42 \mathrm{rpm}$

$h_{0}=$ initial thickness of specimen

$h_{i}=$ final thickness of specimen

$\Delta h=h_{0}-h_{i}$.

From eq. (2),

$$
\dot{\varepsilon} \simeq 1 \sec ^{-1} \text {. }
$$

$D \simeq 10^{-8} \sim 10^{-10} \mathrm{~cm}^{2} \mathrm{sec}^{-1}$ can be obtained from eqs. (1) and (3), supposing that the dislocation density is $10^{8} \sim$ $10^{10} \mathrm{~cm}^{-2}$. $D$ obtained above corresonds to the diffusion coefficient of the atom $\mathrm{C}$ in $\alpha$-iron at $250^{\circ} \sim 400^{\circ} \mathrm{C}^{(7)}$. This means that at this temperature, the diffusion velosity of the atom $\mathrm{C}$ is enough to react with the moving dislocation and at room temperature the atmosphere does not occur because of an insufficient temperature to diffuse the atom $\mathrm{C}$. The dislocation density of $\alpha$-iron increases with rise of working temperature, but at an excessively high temperature, i.e., above $400^{\circ} \mathrm{C}$, the dislocation density decrease reversely because the dislocation moves with the atom $\mathrm{C}$ and polygonization occurs ${ }^{(8)}$. It must be thought, therefore, that the high density of the hardly movable dislocation which induced the Cottrell atmosphere, that is, a large strengthening of $\alpha$-iron, can be obtained by working at $300^{\circ} \mathrm{C}$.

As mentioned above, it can be thought that the strengthening of $\alpha$-iron by warm working is based on the increase in dislocation density by the repetition of multiplications of dislocations and the reaction of dislocations with the interstitial atom $\mathrm{C}$, i.e., dynamic

(4) W. C. Johnston : J. Appl. Phys., 33 (1962), 2716.

(5) A.H.Cottrell : Dislocation and Plastic Flow in Crystals, (1956), Oxford, p. 136.

(6) Tekkogijutsu Kenkyukai : Atuen Riron to Henkei Teiko, Seibundo Shinkosha, p. 235.

(7) J. D. Baird : Iron \& Steel, 36 (1963), 237.

(8) J. D. Baird : Iron \& Steel, 36 (1963), 186. strain aging. On the other hand, the multiplication of dislocations can be obtained by cold working after building-up of the atmosphere and building-up of the atmosphere by static strain aging. So the same strengthening as that by warm working can be obtained by a large number of repetitions of cold working and static strain aging. Fig. 10 shows the effect of the repetition of cold working and static strain aging on the strengthening of $\alpha$-iron in comparison with that of warm working. The curve $I$ in Fig. 10 shows the strengthening by warm working at $300^{\circ} \mathrm{C}$, the curve II by the repetition of cold working and strain aging at 300 ${ }^{\circ} \mathrm{C}$ for $30 \mathrm{~min}$, the curve III by strain aging after cold working, and the curve IV by cold working. From this figure, it will be seen that the strengthening by the repetition of cold working and static strain aging approaches the strengthening by warm working. The phenomenon occurred in warm working, therefore, can be regarded as that due to the repetition of working and strain aging.

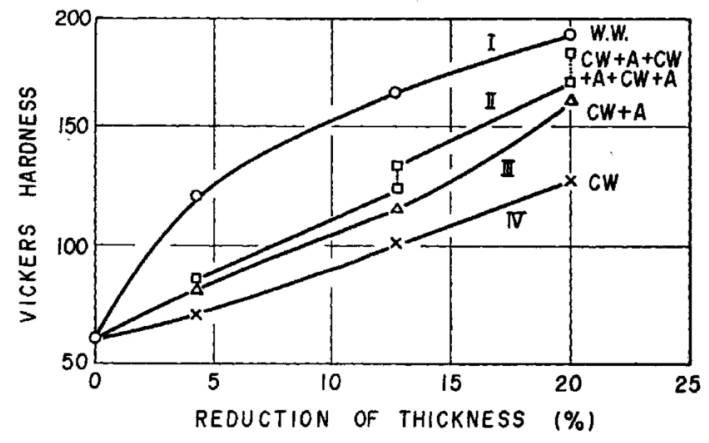

Fig.10 Effect of combination of cold working and strain aging on strengthening of $\alpha$-iron

\section{Conclusions}

The results of the experiment may be summarized as follows :

(1) Both the low temperature annealing effect after cold working and warm working contribute mostly to the strengthening of $0.02 \% \mathrm{C} \alpha$-iron in the same way as for other steels, so that the strengthening mechanism of $0.02 \% \mathrm{C} \alpha$-iron is considered to be the same as that of other steels.

(2) The strength of the warm-worked steel is higher than that of the steel annealed at various temperatures for various times after cold working.

(3) The dislocation density of $\alpha$-iron worked at $300^{\circ} \mathrm{C}$ is higher than that of $\alpha$-iron worked at other temperatures and annealed after cold working. The dislocation density of $\alpha$-iron corresponds to the hardness of $\alpha$-iron.

(4) The strengthening mechanism of $\alpha$-iron by warm working is based on the increase in dislocation density by the multiplication of dislocations due to dynamic strain aging. 